\title{
Putting the Social into Personal Identity: The Master Narrative as Root Metaphor for Psychological and Developmental Science
}

\author{
Commentary on McLean and Syed \\ Phillip L. Hammack Erin E. Toolis \\ University of California, Santa Cruz, Calif., USA
}

Key Words
Culture $\cdot$ Identity $\cdot$ Interpretive $\cdot$ Master narrative

\begin{abstract}
"In the social jungle of human existence, there is no feeling of being alive without a sense of identity." [Erikson, 1968, p. 130]

“The 'methodology of causation' can neither capture the social and personal richness of lives in a culture nor begin to plumb their historical depth. It is only through the application of interpretation that we, as psychologists, can do justice to the world of culture." [Bruner, 1990, p. 137]
\end{abstract}

On a hot summer night in Tel Aviv in 2005, a 17-year-old Jewish Israeli named Ayelet ${ }^{1}$ shared her views on a particularly divisive issue in the Israeli-Palestinian conflict as part of a life-story interview:

As much as I want to understand them [the Palestinians], I can't give up my country. I can't give up Jerusalem. As much as I don't live there and I don't really go to the Wall and everything and don't pray and I'm not that religious. But still it's important for me, for my people.

Just one year prior, during our initial life-story interview, Ayelet had passionately argued for the division of Jerusalem in the interest of peace [see Hammack, 2011a]. Now, one year later, and interestingly one year after she has engaged with Palestinians in intergroup dialogue, Ayelet presents a personal narrative subordinate to a collective, master narrative in which the discursive demands of social identity reign supreme. No longer do Ayelet's personal views on Jerusalem matter, for what matters to Ayelet is that her personal narrative aligns with a master narrative of a particular

${ }^{1}$ Pseudonym.

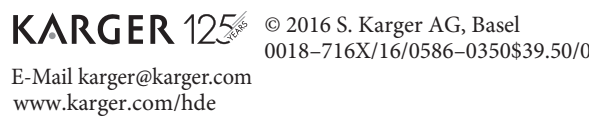

Phillip L. Hammack

Department of Psychology

University of California, Santa Cruz

1156 High Street, Santa Cruz, CA 96064 (USA)

E-Mail hammack@ucsc.edu 
place - Jerusalem - and its significance to the collective. To make meaning of Ayelet's personal narrative, we need to recognize the salience of social identity in the course of human development. And we need to recognize the inherent limits to agency involved in the identity development process - a recognition facilitated by the internalized social speech [Vygotsky, 1978] apparent in her personal narrative.

When Ayelet was interviewed in 2005, the dominant ways of thinking about narrative identity tended to emphasize narratives as long-term autobiographical projects which provide a sense of psychological unity and coherence [e.g., McAdams, 2001], or as discourses with which individuals engage in situated interactions [e.g., Bamberg, 2004; see Thorne, 2004]. Ayelet's narrative could be understood through the prism of both these general approaches. On the one hand, at age 17, she was just beginning to "get a life" [Habermas \& Bluck, 2000] through the initial construction of a life story that could make meaning of her social and political context. Surely shifts over time in narrative content were likely to be part of this psychological project, as she engaged with the "menu" of themes available in her cultural setting [McAdams \& Pals, 2006]. On the other hand, other portions of her interview revealed the process through which Ayelet came to reverse her position on Jerusalem and to emphasize the demands of social identity over time:

[After dialogue], I told my friends what all the Palestinians had said, and they said to me there's no way it could all be true. Like what they said about the checkpoints and ... the injustices, or ... stuff that goes on in the West Bank with the army ... it's just not true. I think they were just exaggerating it.

This excerpt from Ayelet's narrative suggests that through interactions with peers after dialogue, she came to change her position on peace, justice, and the Palestinians. These situated interactions served to consolidate allegiance to her ingroup and the "master narrative" of a particular place and its collective significance Ayelet perceived as dominant at the time.

To make meaning of these types of narratives, it seemed at the time (2005-2006) that the two perspectives on narrative identity development - one that emphasized autobiographical projects and one that emphasized narrative in discursive interaction called for integration. Just as we needed to put "the person into social identity" [Thorne, 2004], we needed to put the social into personal identity. In this theoretical climate, we began to develop our framework of master narrative engagement [see Cohler \& Hammack, 2007; Hammack, 2006, 2008, 2010, 2011a, b; Hammack \& Cohler, 2009].

The qualitative, interpretive approach to narrative we applied allowed us to make meaning of these shifts in Ayelet's engagement with, and internalization of, master narratives over time, for it allowed us to not just take Ayelet's personal narrative at "face value," applying a "hermeneutics of faith" [Josselson, 2004]. Rather, our interpretive approach allowed us to "plumb the historical depth" [Bruner, 1990] of Ayelet's life and to see the way in which her social location as a secular Jewish Israeli narrating a life story at a time of rising religious nationalism created particular pressures to internalize a new master narrative. Consistent with the epistemological underpinnings of narrative psychology [e.g., Bruner, 1990; Cohler, 1982; Polkinghorne, 1988], our interpretive approach allowed us to apply a "hermeneutics of suspicion" [Josselson, 2004] in which we could deeply interrogate Ayelet's production of a personal narrative over time. Applying narrative methods not just at the level of the person but also at the level of the culture, documenting not just the discourse of Ayelet's personal 
narrative but also the multiple discourses that proliferated in her social ecology of development and created multiple master narratives to which she was exposed [Hammack, 2011a], we developed a theory and an approach to the study of narrative, identity, and culture that emphasized the mutual constitution of persons and settings through a process of narrative engagement [Hammack, 2008, 2011a, b].

The idea of master narrative engagement was intended to provide an integrative theory of human development, anchored in several long-established social science paradigms, grounded in the idea that persons and settings - selves and societies - are mutually constituted through a dynamic engagement with the symbolic meaning system of language in its storied form. Beyond anchoring perspectives on narrative identity development [e.g., Bruner, 1990; Cohler, 1982; McAdams, 1996, 2001], life course developmental theory [e.g., Elder, 1998], and cultural psychology [e.g., Shweder, 1990], theoretical inspirations for the framework included Eriksonian identity theory [e.g., Erikson, 1959], cultural-historical activity theory [CHAT; e.g., Vygotsky, 1978], symbolic interactionism [e.g., Mead, 1934], social identity theory [Tajfel \& Turner, 1986], and Foucault's theory of discourse and subjectivity [e.g., Foucault, 1978, 1982]. This theoretical anchoring allowed us to moderate the historical emphasis on personal agency in some theories of narrative and identity [e.g., McAdams, 2001] with perspectives that emphasized the power of social structures and the social categorization process to shape individual subjectivity [e.g., Foucault, 1978; Tajfel \& Turner, 1986]. Cultural psychology's thesis of mutual constitution through linguistic mediation [e.g., Bakhtin, 1981; Vygotsky, 1978], as well as symbolic interactionism's thesis of self-development through social interaction and the "conversation of gestures" [Mead, 1934], provided us with a dynamic way of theorizing the link among narrative, identity, and culture [see Hammack \& Toolis, 2015].

Over time, the framework of master narrative engagement has come to infuse all of our empirical work, guiding us toward diverse areas of inquiry, united in the fundamental premise that it is through a dynamic engagement with master narratives that both individual and societal/cultural development proceed [Hammack \& Toolis, 2015]. In other words, we saw the idea of master narrative engagement as providing not just a framework for thinking about individual lives but also as a framework for thinking about social change. The reproduction or repudiation of master narratives in the course of development was conceived as the empirical window into the trajectory of an individual, a group, a society [e.g., Hammack, 2008, 2011a]. In the language of Kuhn [1962], the idea of the master narrative became the paradigm through which we viewed our own scientific enterprise, and we hoped to stimulate others to see the value in this concept. In the language of Sarbin [1986], following Pepper [1942], we saw the master narrative as a root metaphor for not just psychological and developmental science, but for social science more broadly [Hammack \& Pilecki, 2012].

Thus it is with great enthusiasm that we comment upon the framework proposed here by McLean and Syed [this issue] - a framework that we are gratified to say has been heavily influenced by our ideas, as well as many others in the broader field of narrative psychology. In the remainder of this commentary, we highlight points of overlap and distinction between the two frameworks. First, we suggest that, although the master narrative concept and underlying theory proposed by McLean and Syed overlaps considerably with our theory of master narrative engagement, they offer a valuable elaboration and extension that we suspect will be enormously useful to the field. They imbue the master narrative concept we and others have discussed at length 
with more specificity and precision, and hence McLean and Syed's framework is likely to be highly generative of new empirical work that can make use of their taxonomic system. As part of our discussion of conceptual overlap and distinction, we clarify the emphasis on structural constraint over agency in our own framework. We highlight the key distinction between frameworks in a discussion of interpretive versus post-positivist epistemologies to the study of narrative identity development. We conclude by returning to the idea of the master narrative as root metaphor for psychological and developmental science.

\section{Master Narrative: Concept and Theory}

McLean and Syed suggest that the term "master narrative" has been used in multiple and perhaps inconsistent ways in the literature, and they seek to offer "a clear set of principles that define what master narratives are" and "an articulation of the different types of master narratives." When we began to use the term "master narrative" to describe stories of collective history and identity young Israelis and Palestinians seemed to be appropriating in their personal narratives [Hammack, 2006], we were inspired not only by psychological and developmental scientists [e.g., Bamberg, 2004; Thorne \& McLean, 2003] but also by historians, sociologists, and other social scientists who were speaking of narrative (though not necessarily using the term "master") in a similar vein [e.g., Somers, 1994; Suny, 2001]. As it had been deployed at the time, master narratives were chiefly about social categories such as gender. Bamberg [2004], for example, viewed master narratives as "preexisting normative discourses" (p. 331). The most important feature here lay precisely in the term master: these are compulsory discourses - storied language that individuals feel compelled to internalize and reproduce to maintain a particular social order. That idea resonated very strongly with the narrative data young Israelis and Palestinians were providing, though the narratives they seemed to be appropriating were not just about a social category; they contained prescriptive elements about the form a life story should take, as well as about events and places (e.g., Jerusalem) significant to the group.

As we began to use the term in our own empirical work and to think more theoretically about the relationship between personal and master narratives, we also saw the lack of a clear definition of the concept, in spite of its intuitive appeal. We first defined a master narrative as a "cultural script or 'dominant discourse' that proliferates in a society" [Hammack, 2009, p. 51]. Inspired by Thorne and McLean [2003] and Bamberg [2004], we thought of master narratives as not just about historical events or collective memories but also about the basic meaning of social categories: "[Master narratives are] dominant scripts which can be identified in cultural products and discourse (e.g., media, literature, film, textbooks). These scripts contain collective storylines that range from a group's history to notions of what it means to inhabit a particular social category" [Hammack, 2010, p. 178]. In this definition, we expressed precision in precisely where to look for master narratives in empirical work (i.e., cultural products or artifacts and discourse), and we implicitly provided our own typology: master narratives are about events (i.e., history) and groups (i.e., social identities).

McLean and Syed define master narratives as "culturally shared stories that tell us about a given culture, and provide guidance for how to be a 'good' member of a culture; they are a part of the structure of society." Here we find overlap between our 
own definition of master narrative and theirs, though our definition is perhaps more limiting (even if more precise in terms of guiding empirical inquiry) in its emphasis on history and social identity. They usefully make explicit in their definition the prescriptive nature of master narratives, suggesting that internalization of the master narrative brings with it social value for the "good" life. On issues of basic definition, though, the idea of master narrative within McLean and Syed's framework is consistent with prior conceptions.

The novelty and conceptual innovation in McLean and Syed's framework emerges in the extraordinarily useful set of principles and the taxonomy for master narratives they posit. The theoretical innovation of their framework lies here because it offers a new account of how and why individuals may internalize or reject - reproduce or resist - narratives in the course of development. They offer a useful elaboration on the compulsory nature of master narratives, as well as their utility, ubiquity, and rigidity. These are essential "properties" of master narratives that have gone unarticulated in the literature but that help us to develop parameters of what we might expect as we study narrative identity development.

The further generativity - perhaps the most generative aspect - in McLean and Syed's framework lies in the typology or taxonomy of master narratives they propose. As we have noted, master narratives have typically been posited in the domains of history (i.e., events) and social identity (i.e., groups), but McLean and Syed rightly note that there are other domains and other ways of thinking about the classification of master narratives. The particular way of telling a life story is itself a master narrative, as they suggest in their notion of the "biographical" master narrative. Our analysis of the formal properties of Israeli and Palestinian life stories revealed to us not just the historical or identity-based content these young people were internalizing but also the very way a life ought to be told in these distinct societies [Hammack, 2006, 2011a]. For example, we found that Palestinians almost universally constructed contaminated or tragic life stories, whereas Jewish Israelis constructed redemptive life stories [using the taxonomic system developed by McAdams \& Bowman, 2001]. These life-story forms, we argued, were directly connected to collective expectations of what constitutes a "good" autobiography, consistent largely with the political aims of the group [Hammack, 2011a]. McLean and Syed's framework would have been quite useful for us to consider the different elements of master narratives these young people were internalizing and reproducing. No doubt it will provide an invaluable heuristic for future research on narrative and identity.

Interestingly, McLean and Syed subsume what we might call the social-categorical master narrative (i.e., the expected storyline about the meaning of a particular social category or social identity) within the biographical master narrative, suggesting that diversity in how biographical narratives are constructed depends upon various social categories, offering the examples of women, Black Americans, and sexual minorities in the United States. We prefer to think of these types of master narratives as their own distinct "kind," chiefly because we place great emphasis on the process of social categorization and its implications for human development in all of our work [e.g., Pilecki \& Hammack, 2014; Toolis \& Hammack, 2015]. In our view, subsuming the social-categorical master narrative within the biographical privileges personal identity by suggesting that individual cognition about the life story precedes consideration of social cognition. We come from a position that, as the title of this commentary suggests, privileges the significance of social categorization and its impact on 
human development. Hence we prefer to think of these different "types" of master narratives "on the same metric" (to borrow a phrase from McLean and Syed). Regardless, we suspect that the basic typology for master narratives McLean and Syed propose will prove remarkably generative for the field, even as it may be adapted or elaborated by future researchers.

The general concept of the master narrative thus overlaps between McLean and Syed's framework and our own, but they have offered an invaluable elaboration and expansion in their articulation of a set of principles that define master narratives and a typology for classifying different kinds of master narratives. The assumptions and basic premises between the two frameworks, we suggest, are also overlapping. In other words, the theory at the root of their framework is consistent with the premises of master narrative engagement.

In another point of convergence, McLean and Syed propose a vision of identity development "that attends to both the individual as well as the cultural structures in which the individual develops and, importantly, captures the dynamics of that relationship." Inspired chiefly by Erikson [1959, 1968], they propose a framework of identity as the conceptual link between self and society.

We propose that the concept of master narratives provides a framework for understanding the nature of this intersection between self and society ... As individuals construct a personal narrative, they negotiate with and internalize these master narratives - they are the material they have to work with to understand how to live a good life.

For McLean and Syed, the master narrative concept represents the ideal prism through which to interrogate the self-society link, and they emphasize the importance of thinking of narrative not as "product" but also as "process."

In these core claims about their framework, we find strong echoes of our theory of master narrative engagement, the central tenet of which is that human development is characterized by a dynamic process through which individuals and societies negotiate the meaning of lives, events, and groups through an engagement with narratives [e.g., Hammack, 2008, 2010, 2011a, b]. We described identity as

... ideology cognized through the individual engagement with discourse, made manifest in a personal narrative constructed and reconstructed across the life course and scripted in and through social interaction and social practice. In this way, the content of identity is inherently ideological, assuming a narrative structure and realized in and through social experience. [Hammack, 2008, p. 230]

Here we were inspired by Erikson $[1959,1968]$ to think about master narratives as conveying an ideology - a system of beliefs about the world that says something about one's social and political location [see also McAdams, 2001]. This terminological distinction hints at an important addendum to theories of narrative and identity we made early on and have continuously made over the course of our research: narratives are not "neutral" but assume an ideological position with implications for the social order. Identity is both process (it is made through social practice) and product (it is codified in the personal narrative that integrates the discourse of master narratives), but identities are always constructed from social and political locations [Hammack, 2008; Hammack \& Toolis, 2015]. Consistent with social identity theory, we argue that the identity development process fundamentally involves a competition of value-laden discourses with implications for power and status at both the individual and col- 
lective levels [Hammack \& Toolis, 2015]. Hence whether a young Jewish Israeli appropriates the discourse of united (the dominant perspective) versus divided (the marginalized perspective) Jerusalem has significant implications for the social location of the person. (Ayelet positions herself with the far "left" in Israel when she argues for a divided Jerusalem and with the more dominant "center" or "right" when she argues for united, Israeli-controlled Jerusalem.) Our point here is that identity development is a deeply social and political process and product of human development, and our framework sought precisely to inject the field of narrative and identity with a perspective that highlighted the social and political.

A core part of our theory of identity, and a point of divergence especially from existing perspectives in psychological and developmental science at the time, was the notion that individuals are fundamentally constrained in the course of narrative identity development. We sought to challenge dominant perspectives that either implicitly or explicitly privileged the largely agentic person, constructing a life story from available "themes" and "menus," free to choose at will what may constitute the "good" life [e.g., McAdams \& Pals, 2006]. That all of our empirical work occurred with groups at the margins - Palestinians living under military occupation, Israelis living in the context of historical persecution and existential insecurity, sexual and gender identity minorities living in the contexts of heterosexism and cisgenderism, unhoused individuals living in the context of stigma and economic subordination - led us to question the implicit emphasis on personal agency in most theoretical statements on narrative.

\begin{abstract}
The main distinction between McAdams's overall theoretical framework and the one advanced in this article is primarily connected to the emphasis on culture and the role of agency in identity development. Likely because his work is based in the American cultural context, McAdams's approach tends to ascribe significant agency to individuals as they construct their life stories. In the perspective advanced here, I want to suggest that the relationship between a master narrative and a personal narrative is highly contingent on the cultural context of development. As a consequence, the agency that individuals possess to construct life stories varies considerably [e.g., Hammack, 2006], and it is precisely the cultural conditions of this variability that require empirical and theoretical attention in social, personality, and cultural psychology. [Hammack, 2008, p. 236]
\end{abstract}

Our framework, then, diverged from dominant perspectives on narrative and identity in its relative emphasis on the constraints individuals face in the identity development process, chiefly as a result of their social identities, always positioned in some relation to a power structure in society.

Given the relative emphasis on constraint in our framework, we were surprised at McLean and Syed's claim that we emphasize agency, as well as their suggestion that the terminology of "engagement" itself evokes a greater sense of agency in the process of identity development. Our use of the term "engagement" was meant to evoke a more dynamic but essentially identical process of "internalization" of "social speech" [Vygotsky, 1978] in which they seem to anchor their framework. Here there is a strong balance between agency and structure. On the one hand, social speech proliferates and exists as part of a "verbal-ideological community" inherently political [Bakhtin, 1981; Volosinov, 1929/1973; see Hammack \& Toolis, 2015]. On the other hand, inner speech becomes manifest as individuals encounter the symbolic meaning system of language and learn through social practice [Vygotsky, 1978]. The key theoretical point here is that the existence of social speech precedes the development of inner speech and hence the internalization process is always first constrained by the 
content and structure of master narratives. In concluding one of our first empirical papers on Israeli and Palestinian youth, the relative emphasis on structural constraint over agency is clearly articulated:

Although this study reveals the possibilities of cultural transformations through the ideologies of a new generation, it also reveals the limits of agency in human development. The context of conflict creates unique challenges for adolescent identity development, and the malleability of identity polarization may indeed be limited by a social structure characterized by the perception of existential threat and the need for ingroup solidarity. [Hammack, 2006, p. 362]

A claimed emphasis on agency in our empirical work on narrative identity thus represents something of a misread, since our point of departure is always the social context and its matrix of social categories [consistent with social identity theory; Tajfel \& Turner, 1986]. That we note and emphasize moments of "agency" in which individuals defy the expectations of conformity to a master narrative should not be read as a theoretical emphasis on agency but rather as an interesting finding that emerges from our typically inductive, qualitative, and interpretive approach to the study of lives in context. Thus while we dispute McLean and Syed's claim that we (over)emphasize agency, we wholeheartedly agree with their position that agency has been historically overrepresented in research on narrative identity development and that we must do a better job of attending to the constraints individuals face as they attempt to resist master narratives, especially in situations of social injustice.

Our narrative analysis of the lived experiences of homeless youth [Toolis \& Hammack, 2015] highlights our approach and the way in which, in the process of master narrative engagement, individuals are forced to grapple with constraining master narratives in narrating their sense of self. Each of the participants' stories in that study voiced immense frustration with the lack of power that they held at home and in schools, programs, and shelters, where they were frequently perceived as delinquent or incompetent. McLean and Syed write that our analysis neglects to examine the lack of "actual agency to address the societal constraints and narratives that maintain income inequality." Yet we argue that this is precisely what our findings highlight. One participant, Alejandro, articulated a painful awareness of the inequality and structural barriers that constrained his life chances:

I thought I was just gonna finish high school and go to college. I thought all these thing were gonna be open for me. What happened to this, this dream that you see on TV? ... It doesn't go for the people who are at the bottom. You don't get that ... You gotta dig for the things you want. You gotta scrape for the things you want.

Our analysis was clear to note that the youth in the study were not free to tell just any story - they were forced to contend with not only economic hardship but also the stigmatizing master narrative of the American Dream, which attributes poverty and homelessness to individual characteristics [Bullock, 2008; Limbert \& Bullock, 2009], in making meaning of their experience. Indeed, the individuals interviewed struggled with being perceived as unruly, unmotivated, criminal, and pathological. Because this master narrative is so powerful, we found it especially striking that each of these youth's stories demonstrated resistance to internalizing a sense of personal fault or failure, instead calling attention to structural disadvantage by highlighting the discrimination, violence, neglect, and alienation they faced. Agency emerged as a salient theme in these cases precisely because it had been denied so constantly throughout their lives. We did 
emphasize agency when it occurred in the personal narratives of these youth because it pointed us toward the process of resistance to the hegemonic character of master narrative engagement which underlies our broader theory [e.g., Hammack, 2008].

These findings illustrate the value in taking an interpretive approach to the study of lived experience that considers not just personal meaning making but also the social and political location from which meaning is made. Individuals without housing are all too often treated as passive objects rather than active partners in shaping the institutions and policies that affect their lives. Thus, we feel that it is important to highlight and take seriously the oppressive constraints posed by master narratives while simultaneously considering the plural and often contested ways in which individuals make sense of those narratives in constructing their lives.

We are aware that psychological research has a history of presenting marginalized individuals as passive and deficient and that the study of oppression has historically eclipsed the study of resistance [Apfelbaum, 1979; Haslam \& Reicher, 2012; hooks, 1990]. The need to account for (and promote) social change, and to acknowledge participants as co-constructors of knowledge, is critical and has been noted by scholars in feminist psychology [Moane, 2003; Unger, 1998; White, 2006; White \& Rastogi, 2009], liberation psychology [Freire, 1970; Martín-Baró, 1994] and community psychology [Langhout, 2005; Rappaport, 2000]. Rather than dualistically cast subjective personal experience as distinct from the objective "facts on the ground," as the authors do here, our concept of master narrative engagements seeks to transcend the false dichotomy of agency versus structure by arguing that meaning does not exist exclusively in the mind or in the external world, but is mutually constituted by their interaction [Hammack, 2010].

In sum, the master narrative concept and the underlying theory of identity are virtually identical between McLean and Syed's framework and our theory of master narrative engagement. In contrast to McLean and Syed's claims, the frameworks also converge in their relative emphasis on social structure to constrain personal agency in the identity development process and to shape the way in which individuals negotiate and internalize master narratives. The development of Ayelet's personal narrative over time illustrates the limiting properties of master narratives. McLean and Syed propose a useful and novel elaboration of the master narrative concept by articulating principles and developing a typology with which we concur, with the exception of their choice to subsume social-categorical master narratives within the biographical. The key divergence between the frameworks is less theoretical and more epistemological. Our theory of master narrative engagement is anchored in an interpretive epistemology that emphasizes qualitative methods, while their framework strives to inspire a more quantitative approach to the empirical study of master narratives in a post-positivist epistemology. We view this aspect of divergence as entirely complementary, and we use the remainder of this commentary to discuss these distinct epistemological stances toward master narratives.

\section{Epistemologies of Narrative Inquiry}

McLean and Syed propose their master narrative framework at a time of incredible flourishing of narrative theory and methods in psychological and developmental science, as well as the decided recognition of qualitative methods as a legitimate form 
of psychological inquiry [e.g., Gergen, Josselson, \& Freeman, 2015]. The genesis of this flourishing can be traced to several key works of the 1980s that argued for a paradigm shift - a "scientific revolution" [Kuhn, 1962] - in how we think about human development and the relationship between mind and society [e.g., Bruner, 1987, 1990; Cohler, 1982; McAdams, 1988; Polkinghorne, 1988; Sarbin, 1986]. This shift was intended at least in part to challenge hegemonic forms of inquiry in psychology, anchored in the positivist and post-positivist impulse to produce knowledge more concerned with prediction and control than description and understanding of human lives [e.g., Bruner, 1990]. What united these key works was at least in part a revitalization of an interpretive epistemology that had been delegitimized and marginalized in psychological science for nearly all of the twentieth century [see Tappan, 1997]. At the heart of the interpretive approach is the notion that identity and human experience can be understood as a dialogic co-construction of meaning that develops across the life course [Cohler, 1982]. As Cohler [1982] explained, "This interpretive approach to the study of the person parallels the approach actually used by persons in the successive interpretations or reconstructions of their own" (p. 229).

The interpretive approach has important implications for social justice. As McLean and Syed suggest, master narratives draw their power in part from their invisibility and from their ability to appear natural, singular, and immutable. These qualities allow master narratives to maintain the status quo by portraying oppression and domination as natural and inevitable [Apfelbaum, 1979]. Researchers can unwittingly collude in the reification of social categories by taking them for granted, thereby undermining possibilities for social change [Haslam \& Reicher, 2012; Reicher \& Hopkins, 2001]. Because an interpretivist stance approaches psychological phenomena as socially constructed and dynamic, it is particularly well equipped to interrogate the taken-for-granted "facts" of social reality and pave the way for applications that could provide voice to the historically marginalized and subordinated [e.g., Sampson, 1993; Smith \& Sparkes, 2008; White \& Dotson, 2010]. An interpretive analysis allows for multiple (and often contested) perspectives and facilitates a consideration of meaning construction as an inherently social and political process rather than merely a reflection of the natural order of things.

Given the centrality of the interpretive epistemology to narrative psychology and the concordance between an interpretive epistemology and the theoretical premises of both our framework and McLean and Syed's, we were surprised that McLean and Syed state that one of their goals is to move the study of master narratives away from an emphasis on the interpretation of experiences and toward a more post-positivist paradigm. They suggest that in the interpretive approach, "stories are read at face value and allowed to "speak for themselves"' and that such an approach does not allow for an analysis of "facts on the ground that may contradict or constrain the story." Yet this goal seems to rest on a fundamental misunderstanding of interpretive approaches, which necessarily take a holistic approach to textual analysis and typically involve a deep understanding of the person and his or her social location [Lieblich, TuvalMashiach, \& Zilber, 1998; Mishler, 1999, 2004]. This idea is particularly well argued in Josselson's [2004] landmark essay arguing for the importance of integrating two approaches in narrative analysis - an approach grounded in a "hermeneutics of faith" (where the speaker's text is analyzed at "face value") and a "hermeneutics of suspicion" (where the analyst brings the lens of suspicion to the text, integrating data about the individual's life and social location from beyond the text). Even if McLean and Syed's 
point is that those who take a post-positivist approach ought to integrate a "hermeneutics of suspicion" into their analytic practice, we are concerned that they associate the practice of "interpretation" exclusively with a "hermeneutics of faith." We believe both epistemologies ought to integrate these hermeneutics, but McLean and Syed fail to acknowledge that the examination of "objective constraints" can be usefully undertaken in either an interpretive or post-positivist epistemological framework.

McLean and Syed allude to a privileging of post-positivist approaches to master narrative over interpretive approaches when they suggest that post-positivism is more consistent with their goal of "establishing a clear framework, with definitions, principles, and types of master narratives." The implication is that the previously articulated interpretive approach is unclear, lacks definitions and principles, and offers an inadequate blueprint for empirical work. Rather than thinking of these epistemological approaches in a hierarchical manner, as is unfortunately common in science, we hope that future narrative research might find cause for mutual enrichment and the value of converging, complementary evidence about human development and experience.

The differences in epistemology between these frameworks do, however, suggest implications for distinct lines of empirical work. As interpretivists, our empirical work tends toward inductive, idiographic, holistic, qualitative inquiry. This approach is firmly person-centered and allows for an in-depth exploration of the ways in which individuals make meaning of their personal lived experience in dialogue with cultural and historical context. In contrast, as post-positivists, McLean and Syed's empirical work has traditionally placed more emphasis on aggregated group differences in which narrative data is quantified for the purpose of hypothesis testing [e.g., McLean \& Breen, 2009; Syed \& Azmitia, 2010; Thorne \& McLean, 2002, 2003]. We suggest that both approaches are valuable and can each answer different types of questions. The strength of the interpretive approach lies in exploring questions of coherence and lived experience while limiting a priori assumptions, helping to avoid essentializing groups and reifying differences in social categories. The strength of the post-positivist approach allows for narrative data to be correlated with other quantitative psychological measures, such as self-esteem [McLean \& Breen, 2009], depression [McLean, Breen, \& Fournier, 2010], generativity [McLean \& Pratt, 2006], dispositional optimism [McLean \& Pratt, 2006], self-reported health [McLean \& Fournier, 2008], and personality traits [McLean \& Fournier, 2008]. The post-positivist approach also usefully mobilizes narrative data to link to other theories of identity development in the psychological literature, such as the identity status model and theories of ethnic identity development [Syed \& Azmitia, 2008, 2010]. We hope that, rather than moving the study of master narratives away from interpretive inquiry, the inherent complementarity of our theory of master narrative engagement and McLean and Syed's master narrative framework can generate mutually enriching knowledge on the relationship between selves and societies.

\section{The Master Narrative as Root Metaphor}

In his field-defining essay on narrative, Sarbin [1986] posits narrative as a root metaphor for psychology - a "poetic creation" that "provides the foundation for belief systems that guide action" (p. 5). As we conclude our commentary, we return to a point of convergence between McLean and Syed's framework and our own. Consis- 
tent with McLean and Syed, and expanding upon Sarbin's [1986] proposition, we suggest that the master narrative represents the ideal root metaphor for psychological and developmental science because it provides a vocabulary for understanding the dynamic co-constitution of self and society through the process of (what we call) narrative engagement.

To return to Ayelet's story, it is not simply her capacity to "think, perceive, imagine, and make moral choices according to narrative structures" [Sarbin, 1986, p. 8] that guides development. Rather, it is the fact that this capacity occurs through a dynamic engagement with stories circulating in her ecology of development, presenting fundamental constraints on her process of identity development as she encounters their ubiquity, rigidity, and compulsory nature [McLean \& Syed, this issue]. In the engagement with master narratives, Ayelet's evolving story tells us not just about the nature of human development but also about the process of social and historical stasis and change. Her own "poetic creation" of identity is not just her own; it is "her people's" (to use her own words). And in this observation, rooted in an interpretation of her life story in its particular political context, the significance of the social in identity is apparent - not just for its relevance but for the way that the discourse of the collective populates the discourse of the individual with sometimes profound implications for the social order. (Consider that the status of Jerusalem possesses extraordinary geopolitical significance.)

In our view, these complementary theories - our theory of master narrative engagement and McLean and Syed's master narrative framework - give poetic expression to the lived experience of identity development, pointing we who study this experience to the inherent constraints placed on human development as a function of dominant discourses and compulsory modes of cognition. They highlight the significance of organized language, meaning making, and our dynamic engagement with a social ecology infused with historical imaginaries of a "proper" life course, a "proper" account of social identity, and a "proper" account of collective memory. That individuals may deviate from the press of master narratives, that they may navigate the "social jungle of human existence" [Erikson, 1968] with creativity and defiance, attests to the need for a theory of human development that integrates agency and structure, person and setting, individual and culture. Both our framework of master narrative engagement and McLean and Syed's master narrative framework do a great service for psychological and developmental science by reorienting our root metaphor from the machine of another era to the intentional actor and meaning maker, constrained by culture, liberated by the possibility of social change, united in a quest to achieve a "good" life, even in the midst of obstacle. That we might produce knowledge that captures the dynamism, complexity, and creativity of human development through narrative engagement is an attainable ideal, thanks in great measure to these complementary theoretical frameworks.

\section{Acknowledgment}

Qualitative data excerpts included in this commentary have been previously published in Hammack [2011a] and Toolis and Hammack [2015] and are based on research funded by the University of Chicago, the University of California, Santa Cruz, the Spencer Foundation, and the United States Institute of Peace. We thank Andrew Pilecki for his comments on a draft of this commentary. 


\section{References}

Apfelbaum, E. (1979). Relations of domination and movements for liberation: An analysis of power between groups. In W.G. Austin \& S. Worchel (Eds.), The social psychology of intergroup relations (pp. 188-204). Monterey, CA: Brooks/Cole.

Bakhtin, M.M. (1981). The dialogic imagination (C. Emerson \& M. Holquist, Trans.). Austin, TX: University of Texas Press.

Bamberg, M. (2004). "I know it may sound mean to say this, but we couldn't really care less about her anyway": Form and functions of "slut bashing" in male identity constructions in 15-year-olds. Human Development, 47, 331-353. doi:10.1159/000081036

Bruner, J. (1987). Life as narrative. Social Research, 54, 11-32.

Bruner, J. (1990). Acts of meaning. Cambridge, MA: Harvard University Press.

Bullock, H.E. (2008). Justifying inequality: A social psychological analysis of beliefs about poverty and the poor. In A.C. Lin \& D.R. Harris (Eds.), The colors of poverty: Why racial and ethnic disparities persist (pp. 52-76). New York, NY: Russell Sage Foundation.

Cohler, B.J. (1982). Personal narrative and life course. In P. Baltes \& O.G. Brim (Eds.), Life span development and behavior: Vol. 4 (pp. 205-241). New York, NY: Academic Press.

Cohler, B.J., \& Hammack, P.L. (2007). The psychological world of the gay teenager: Social change, narrative, and "normality." Journal of Youth and Adolescence, 36, 47-59. doi:10.1007/s10964-006-9110-1

Elder, G.H. (1998). The life course as developmental theory. Child Development, 69, 1-12. doi:10.1111/ j.1467-8624.1998.tb06128.x

Erikson, E.H. (1959). Identity and the life cycle. New York, NY: Norton.

Erikson, E.H. (1968). Identity: Youth and crisis. New York, NY: Norton.

Foucault, M. (1978). The history of sexuality: Vol. 1. An introduction (R. Hurley, Trans.). New York, NY: Pantheon.

Foucault, M. (1982). The subject and power. Critical Inquiry, 8, 777-795. doi:10.1086/448181

Freire, P. (1970). Pedagogy of the oppressed. New York, NY: Continuum.

Gergen, K.J., Josselson, R., \& Freeman, M. (2015). The promises of qualitative inquiry. American Psychologist, 70, 1-9. doi:10.1037/a0038597

Habermas, T., \& Bluck, S. (2000). Getting a life: The emergence of the life story in adolescence. Psychological Bulletin, 126, 748-769. doi:10.1037/0033-2909.126.5.748

Hammack, P.L. (2006). Identity, conflict, and coexistence: Life stories of Israeli and Palestinian adolescents. Journal of Adolescent Research, 21, 323-369. doi:10.1177/0743558406289745

Hammack, P.L. (2008). Narrative and the cultural psychology of identity. Personality and Social Psychology Review, 12, 222-247. doi:10.1177/1088868308316892

Hammack, P.L. (2009). Exploring the reproduction of conflict through narrative: Israeli youth motivated to participate in a coexistence program. Peace and Conflict: Journal of Peace Psychology, 15, 49-74. doi:10.1080/10781910802589923

Hammack, P.L. (2010). Identity as burden or benefit? Youth, historical narrative, and the legacy of political conflict. Human Development, 53, 173-201. doi:10.1159/000320045

Hammack, P.L. (2011a). Narrative and the politics of identity: The cultural psychology of Israeli and Palestinian youth. New York, NY: Oxford University Press.

Hammack, P.L. (2011b). Narrative and the politics of meaning. Narrative Inquiry, 21, 311-318. doi:10.1075/ ni.21.2.09ham

Hammack, P.L., \& Cohler, B.J. (2009). Narrative engagement and sexual identity: An interdisciplinary approach to the study of sexual lives. In P.L. Hammack \& B.J. Cohler (Eds.), The story of sexual identity: Narrative perspectives on the gay and lesbian life course (pp. 3-22). New York, NY: Oxford University Press. doi:10.1093/acprof:oso/9780195326789.003.0001

Hammack, P.L., \& Pilecki, A. (2012). Narrative as a root metaphor for political psychology. Political Psychology, 33, 75-103. doi:10.1111/j.1467-9221.2011.00859.x

Hammack, P.L., \& Toolis, E. (2015). Identity, politics, and the cultural psychology of adolescence. In L. Jensen (Ed.), Oxford handbook of human development and culture (pp. 396-409). New York, NY: Oxford University Press.

Haslam, S.A., \& Reicher, S.D. (2012). When prisoners take over the prison: A social psychology of resistance. Personality and Social Psychology Review, 16, 154-179. doi:10.1177/1088868311419864

hooks, B. (1990). Marginality as a site of resistance. In R. Ferguson \& M. Gever (Eds.), Out there: Marginalization and contemporary culture: Vol. 4 (pp. 341-343). Cambridge, MA: MIT Press.

Josselson, R. (2004). The hermeneutics of faith and the hermeneutics of suspicion. Narrative Inquiry, 14, 1-28. doi:10.1075/ni.14.1.01jos

Kuhn, T.S. (1962). The structure of scientific revolutions. Chicago, IL: University of Chicago Press.

Langhout, R.D. (2005). Acts of resistance: Student (in)visibility. Culture \& Psychology, 11, 123-158. doi:10.1177/1354067X05052348 
Lieblich, A., Tuval-Mashiach, R., \& Zilber, T. (1998). Narrative research: Reading, analysis, and interpretation. Thousand Oaks, CA: Sage.

Limbert, W.M., \& Bullock, H.E. (2009). Framing U.S. redistributive policies: Tough love for poor women and tax cuts for seniors. Analyses of Social Issues and Public Policy, 9, 57-83. doi:10.1111/j.15302415.2009.01189.x

Martín-Baró, I. (1994). Writings for a liberation psychology (A. Aron \& S. Corne, Trans.). Cambridge, MA: Harvard University Press.

McAdams, D.P. (1988). Power, intimacy, and the life story: Personological inquiries into identity. New York, NY: Guilford.

McAdams, D.P. (1996). Personality, modernity, and the storied self: A contemporary framework for studying persons. Psychological Inquiry, 7, 295-321. doi:10.1207/s15327965pli0704_1

McAdams, D.P. (2001). The psychology of life stories. Review of General Psychology, 5, 100-122. doi:10.1037/1089-2680.5.2.100

McAdams, D.P., \& Bowman, P.J. (2001). Narrating life's turning points: Redemption and contamination. In D.P. McAdams, R. Josselson, \& A. Lieblich (Eds.), Turns in the road: Narrative studies of lives in transition (pp. 3-34). Washington, DC: American Psychological Association Press. doi:10.1037/10410-001

McAdams, D.P., \& Pals, J.L. (2006). A new Big Five: Fundamental principles for an integrative science of personality. American Psychologist, 61, 204-217. doi:10.1037/0003-066X.61.3.204

McLean, K.C., \& Breen, A.V. (2009). Processes and content of narrative identity development in adolescence: Gender and well-being. Developmental Psychology, 45, 702-710. doi:10.1037/a0015207

McLean, K.C., Breen, A., \& Fournier, M. (2010). Constructing the self in early, middle, and late adolescent boys: Narrative identity, individuation, and well-being. Journal of Research on Adolescence, 20, 166187. doi:10.1111/j.1532-7795.2009.00633.x

McLean, K.C., \& Fournier, M.A. (2008). The content and processes of autobiographical reasoning in narrative identity. Journal of Research in Personality, 42, 527-545. doi:10.1016/j.jrp.2007.08.003

McLean, K.C., \& Pratt, M.W. (2006). Life's little (and big) lessons: Identity statuses and meaning-making in the turning point narratives of emerging adults. Developmental Psychology, 42, 714-722. doi:10.1037/0012-1649.42.4.714

Mead, G.H. (1934). Mind, self and society. Chicago, IL: University of Chicago Press.

Mishler, E.G. (1999). Storylines: Craftartists' narratives of identity. Cambridge, MA: Harvard University Press.

Mishler, E.G. (2004). Historians of the self: Restorying lives, revising identities. Research in Human Development, 1, 101-121. doi:10.1080/15427609.2004.9683331

Moane, G. (2003). Bridging the personal and the political: Practices for a liberation psychology. American Journal of Community Psychology, 31, 91-101. doi:10.1023/A:1023026704576

Pepper, S.C. (1942). World hypotheses: A study in evidence. Berkeley, CA: University of California Press.

Pilecki, A., \& Hammack, P.L. (2014). "Victims" versus "righteous victims": The rhetorical construction of social categories in historical dialogue among Israeli and Palestinian youth. Political Psychology, 35, 813-830. doi:10.1111/pops.12063

Polkinghorne, D. (1988). Narrative knowing and the human sciences. Albany, NY: State University of New York Press.

Rappaport, J. (2000). Community narratives: Tales of terror and joy. American Journal of Community Psychology, 28, 1-24. doi:10.1023/A:1005161528817

Reicher, S., \& Hopkins, N. (2001). Psychology and the end of history: A critique and a proposal for the psychology of social categorization. Political Psychology, 22, 383-407.

-Sampson, E.E. (1993). Identity politics: Challenges to psychology's understanding. American Psychologist, 48, 1219-1230. doi:10.1037/0003-066X.48.12.1219

Sarbin, T.R. (1986). The narrative as a root metaphor for psychology. In T.R. Sarbin (Ed.), Narrative psychology: The storied nature of human conduct (pp. 3-21). New York, NY: Praeger.

Shweder, R.A. (1990). Cultural psychology - What is it? In J.W. Stigler, R.A. Shweder, \& G. Herdt (Eds.), Cultural psychology: Essays on comparative human development (pp. 1-46). New York, NY: Cambridge University Press. doi:10.1017/CBO9781139173728.002

Smith, B., \& Sparkes, A.C. (2008). Narrative and its potential contribution to disability studies. Disability \& Society, 23, 17-28. doi:10.1080/09687590701725542

Somers, M.R. (1994). The narrative construction of identity: A relational and network approach. Theory and Society, 23, 605-649. doi:10.1007/BF00992905

- Suny, R.G. (2001). Constructing primordialism: Old histories for new nations. Journal of Modern History, 73, 862-896. doi:10.1086/340148

Syed, M., \& Azmitia, M. (2008). A narrative approach to ethnic identity in emerging adulthood: Bringing life to the identity status model. Developmental Psychology, 44, 1012-1027. doi:10.1037/00121649.44.4.1012 
Syed, M., \& Azmitia, M. (2010). Narrative and ethnic identity exploration: A longitudinal account of emerging adults' ethnicity-related experiences. Developmental Psychology, 46, 208-219. doi:10.1037/ a001782

Tajfel, H., \& Turner, J. (1986). The social identity theory of intergroup behavior. In S. Worchel \& W. Austin (Eds.), The psychology of intergroup relations (pp. 7-24). Chicago, IL: Nelson-Hall.

Tappan, M.B. (1997). Interpretive psychology: Stories, circles, and understanding lived experience. Journal of Social Issues, 53, 645-656. doi:10.1111/j.1540-4560.1997.tb02453.x

Thorne, A. (2004). Putting the person into social identity. Human Development, 47, 361-365. doi:10.1159/ 000081038

Thorne, A., \& McLean, K.C. (2002). Gendered reminiscence practices and self-definition in late adolescence. Sex Roles, 46, 267-277.

Thorne, A., \& McLean, K.C. (2003). Telling traumatic events in adolescence: A study of master narrative positioning. In R. Fivush \& C. Haden (Eds.), Autobiographical memory and the construction of a narrative self (pp. 169-185). Mahwah, NJ: Erlbaum.

Toolis, E.E., \& Hammack, P.L. (2015). The lived experience of homeless youth: A narrative approach. Qualitative Psychology, 2, 50-68. doi:10.1037/qup0000019

Unger, R.K. (1998). Positive marginality: Antecedents and consequences. Journal of Adult Development, 5, 163-170. doi:10.1023/A:1023019626469

Volosinov, V.N. (1973). Marxism and the philosophy oflanguage (L. Matejka \& I.R. Titunik, Trans.). Cambridge, MA: Harvard University Press. (Original work published 1929.)

Vygotsky, L.S. (1978). Mind in society: The development of higher psychological processes. Cambridge, MA: Harvard University Press. (Original work published 1935.)

White, A.M. (2006). African American feminist masculinities: Personal narratives of redemption, contamination, and peak turning points. Journal of Humanistic Psychology, 46, 255-280. doi:10.1177/ 0022167806286262

White, A.M., \& Dotson, W. (2010). "It takes a village to raise a researcher": Narrative interviewing as intervention, reconciliation, and growth. Journal of Black Psychology, 36, 75-97. doi:10.1177/ 0095798408329945

White, A., \& Rastogi, S. (2009). Justice by any means necessary: Vigilantism among Indian women. Feminism \& Psychology, 19, 313-327. doi:10.1177/0959353509105622 